SOCIAL SCIENCE RESEARCH

Johan Lagerlöf *

Insisting on a Non-Negative Price: Oligopoly, Uncertainty, Welfare, and Multiple Equilibria

* WZB - Wissenschaftszentrum Berlin

SP II 2003- 04

June 2003

ISSN Nr. $0722-6748$

Research Area

Markets and Political Economy

Research Unit

Competitiveness and Industrial Change
Forschungsschwerpunkt

Markt und politische Ökonomie

Abteilung

Wettbewerbsfähigkeit und industrieller Wandel 
Zitierweise/Citation:

Johan Lagerlöf, Insisting on a Non-Negative Price:

Oligopoly, Uncertainty, Welfare, and Multiple Equilibria, Discussion Paper SP II 2003 - 04, Wissenschaftszentrum Berlin, 2003.

Wissenschaftszentrum Berlin für Sozialforschung gGmbH, Reichpietschufer 50, 10785 Berlin, Germany, Tel. (030) 25491 - 0 Internet: www.wz-berlin.de 


\section{ABSTRACT \\ Insisting on a Non-Negative Price: Oligopoly, Uncertainty, Welfare, and Multiple Equilibria}

by Johan Lagerlöf ${ }^{\star}$

I study Cournot competition under incomplete information about demand while assuming that market price must be non-negative for all demand realizations. Although this assumption is very natural, it has only rarely been made in the earlier literature. Yet it has important economic consequences: (1) multiple (symmetric, pure strategy) equilibria can exist, despite the fact that demand and cost are linear; and (2) expected total surplus can be larger when the firms do not know demand than when they do, a result which has important implications for the social desirability of information sharing. The arguments of the paper are relevant also for price competition and for uncertainty about, e.g., cost or the number of firms, and these issues are discussed.

Keywords: Non-negativity constraint, Multiple equilibria, Value of information, Information sharing, Trade associations, Antitrust policy

JEL Classification: D42, D43, D80, L12, L13, L40

For helpful discussions and comments I thank Rabah Amir, Heiko Gerlach, Paul Heidhues, Jos Jansen, Patrick Legros, Inés Macho-Stadler, Nicolas Melissas, Pedro Pereira, Hendrik Röller, Thomas Rønde, Loïc Sadoulet, and the participants of a TMR workshop in Heidelberg (Germany) and seminars at ECARES (Brussels), Catholic University (Louvain-la-Neuve, Belgium), WZB (Berlin), EARIE 2001 (Dublin), and ESEM 2002 (Venice). Financial support from the European Commission (contracts Nos. ERBFMRXCT980203 and HPRN-CT-2000-00061) is gratefully acknowledged. 
Bestehen auf einen nichtnegativen Preis: Oligopol, Ungewißheit, Wohlfahrt und multiple Gleichgewichte

In diesem Beitrag wird Cournot-Wettbewerb bei unvollständiger Information über die Nachfrage untersucht und unterstellt, daß der Marktpreis für alle Realisierungen der Nachfrage nichtnegativ ist. Obgleich diese Annahme sehr selbstverständlich ist, ist sie nur selten in der früheren Literatur verwendet worden. Dennoch hat sie wichtige ökonomische Konsequenzen: (1) können multiple Gleichgewichte existieren (symmetrisch, bei reinen Strategien), obwohl Nachfrage und Kosten linear sind; und (2) kann erwarteter Gesamtüberschuß größer sein, wenn die Unternehmen die Nachfrage nicht kennen als im Falle sie ihnen nicht bekannt ist. Dieses Ergebnis hat wichtige Implikationen für die soziale Erwünschtheit der gemeinsamen Nutung von Information ("Information sharing"). Die Argumente des Beitrags sind auch für Preiskonkurrenz und für Ungewißheit beispielsweise hinsichtlich der Kosten oder der Zahl von Unternehmen relevant. Sie werden abschließend besprochen. 


\section{Introduction}

Firms that are active in oligopolistic markets often face a considerable amount of uncertainty about demand, competitors' costs, and other market features that are important for the firms' decisions. Reflecting this fact, a large theoretical literature has developed that studies firm behavior under such uncertainty. In particular, a significant number of papers have investigated firms' incentives to engage in information sharing, information acquisition, and strategic experimentation. ${ }^{1}$

Although this is a rich literature with many important and useful insights, almost all of its contributions ${ }^{2}$ share an unappealing feature: they make assumptions that imply that either (for those models where firms choose quantities) market price can be negative or (for those models where firms choose prices) firms' output can be negative. The typical justification for making these assumptions is analytical tractability. It is also often argued that, by making appropriate additional assumptions about the distribution of the stochastic variable (e.g., by letting its variance be sufficiently low), one can ensure that a negative price/quantity will occur only with a low probability. ${ }^{3}$ One problem with this argument, however, is that the real-world situations that the models are supposed to capture often involve a substantial amount of uncertainty. One may therefore wonder whether the practice of using models where prices/quantities can be negative makes us overlook valuable insights. ${ }^{4}$

In this paper I argue that we are indeed missing important economic insights by ignoring the non-negativity constraint. In particular, taking the nonnegativity constraint explicitly into account has important implications for (1) the possibility of multiple equilibria and for (2) the desirability (from an ex-

\footnotetext{
${ }^{1}$ For example, papers on information sharing include Clarke (1983), Gal-Or (1985, 1986), Li (1985), Novshek and Sonnenschein (1982), Ponssard (1979), Raith (1996), Sakai and Yamato (1989), Shapiro (1986), and Vives (1984, 1990).

2 The notable exception is Malueg and Tsutsui (1998), which also is the paper that is most closely related the the present one. I will relate my paper to theirs later in this introduction.

${ }^{3}$ See, for example, Vives (1984, p. 77, n. 2; 1999, Ch. 8, n. 6).

${ }^{4} \mathrm{~A}$ common modeling framework is to assume a linear cost function and a linear inverse demand function, $P(X)=a-b X$, where $a$ is stochastic. Each firm observes a private signal $s_{i}$, and the joint distribution of $a$ and $s_{i}$ has the proporty that the conditional expectation function, $E\left(a \mid s_{i}\right)$, is linear. An example of such a distribution, which is often explicitly assumed, is a bivariate normal. If the demand intercept $a$ indeed is normally distributed, then obviously market price will be negative for some realizations, since then $a$ itself can be negative. But also if the distribution is such that $a$ always takes non-negative values, market price will be negative if industry output (which is an endogenous variable) is large enough.
} 
pected total surplus point of view) of the firms' obtaining access to more information. Whether and under what circumstances an oligopoly model can have multiple equilibria is important to know, given that we want to understand our work-horse models well. Such knowledge is, for example, crucial for empirical (e.g., experimental) work, since then the analyst needs to know what behavior theory predicts and whether he or she should be worried about the firms' (or subjects') ability to coordinate on one of the equilibria. A thorough understanding of the welfare implications of better informed firms are of great importance from the point of view of antitrust policy. In particular, the desirability of regulatory measures that discourage or encourage information sharing among firms critically depends on this issue. ${ }^{5}$

The formal setting in which I will develop my arguments is a traditional Cournot model. Following a large part of the literature, I assume that the inverse demand function is linear and that the uncertainty concerns the intercept of this function. For simplicity, all firms face the same uncertainty, so information is incomplete but symmetric. Moreover, all firms have the same constant marginal cost technology. The special feature of the model is the assumption that market price must be non-negative for all demand realization. That is, if the firms have been optimistic about demand to such an extent that a negative price is required for the market to clear, then market price simply equals zero. ${ }^{6}$

The reason why this model gives rise to a multiplicity of equilibria is that the uncertainty about (inverse) demand together with the assumption that market price cannot be negative make the expected (inverse) demand function convex. It is well known that a Cournot model with known demand may have multiple equilibria if the demand function is sufficiently convex. Intuitively, for a demand function that is convex enough, the choice variables (i.e., the output levels) of a typical firm and one of its competitors are strategic complements: the marginal profit of a typical firm increases with the output of its competitor. As a result,

\footnotetext{
${ }^{5}$ For discussions of such regulatory measures, see Kühn and Vives (1995) and Kühn (2001).

${ }^{6}$ The fact that market price on these occasions is zero should not be interpreted too literally. A richer model, which I conjecture would give rise to qualitatively the same results as here, could assume that there are (constant unit) costs associated with selling the good. If market price falls below this cost level, the firms will prefer not to sell. In such a model, the nonnegativity constraint assumed in the present paper would refer to the market price net of selling costs, and it could thus be binding also for a strictly positive (gross) market price.

Another way of thinking about the non-negativity constraint would be that it refers to the market price net of marginal cost, and that there is a regulatory rule that makes a negative such net price illegal (justified by concerns for limit pricing).
} 
multiple equilibria can be sustained through self-fulfilling beliefs on the part of the firms. In the model studied in the present paper, where demand is known to be linear but has an unknown intercept, a convexity of the expected demand schedule arises naturally because of the non-negativity constraint on price, and this creates a multiplicity of equilibria for the same reason as in a model with known and sufficiently convex demand. ${ }^{7}$

The reason why informed firms can be detrimental to expected total surplus is that if a firm chooses a relatively large quantity and demand turns out to be low, its losses will, because of the non-negativity constraint on price, be limited to its production costs. Relative to a model in which price can be negative, this makes the firm bolder (or more aggressive) when choosing its output: it chooses a larger quantity than it would have done without the non-negativity constraint, which is good for the consumers and for total surplus. This "boldness effect" is particularly strong for low values of the marginal cost parameter, since then the overall production costs are low. As a consequence, for that part of the parameter space, uninformed firms are beneficial to expected total surplus given that we impose the non-negativity constraint, a result that cannot occur in the Cournot model without this constraint. ${ }^{8}$

The paper that is most closely related to the present one is Malueg and Tsutsui (1998). ${ }^{9}$ By means of a numerical duopoly example, they show a result that is quite similar (although not identical) to the welfare result discussed above. They therefore deserve credit for the observation that information sharing can reduce social welfare in a Cournot model with demand uncertainty when the non-negativity constraint on price is explicitly taken into account. The modeling framework they use, however, is primarily designed for the particular purpose of

\footnotetext{
${ }^{7}$ In a complete information Cournot model more generally (also in symmetric versions of this model), there can exist multiple equilibria of another kind, namely equilibria in which one firm or a subset of firms produce a positive quantity whereas the others are inactive, producing nothing; see Amir and Lambson (2000). Such equilibria will not exist, however, in the model that I investigate.

The standard formulation of the linear-quadratic Cournot model with incomplete information — which allows for negative prices and quantities — does have a unique equilibrium. This is typically proven by rewriting (using a technique suggested by Basar and Ho, 1974) a firm's payoff function in a way that does not alter the first-order condition but which transforms the problem into a team decision problem. Then a uniqueness theorem due to Radner (1962) can be used. See, for example, Vives (1999).

${ }^{8} \mathrm{~A}$ more detailed review of the relevant literature will be provided later in the paper.

${ }^{9}$ This relatively short article in the Australian Economic Papers came to my attention I am grateful to Jos Jansen for finding it - in February 2003, two and a half years after I had finished the first version of the present paper.
} 
investigating the profitability of information sharing between firms, as it assumes that firms have private information which they may or may not want to share. My model cannot address questions about information sharing directly, since it assumes that information is symmetric (although incomplete), but instead it can study the effects of providing all firms with the same additional information. Thanks to this modeling approach my analysis becomes much more tractable than theirs, which makes it possible not just to note that better informed firms can, under some circumstances, be bad for welfare, but also to derive insights into what these circumstances look like in terms of the cost parameter and the number of firms in the industry. (The multiplicity result discussed above is, to the best of my knowledge, completely novel.)

Although the arguments of the paper are developed in a Cournot setting and with uncertainty about the demand intercept, the points I make are relevant also under other assumptions. Later in the paper I will discuss the effects of imposing a non-negativity constraint on quantities in the Bertrand model (see the end of Section 2.2) and the consequences of assuming uncertainty about other parameters than the demand intercept (see the concluding section).

The remainder of the paper is organized as follows. In the next section a model with two states is described and analyzed, and the multiplicity result and the welfare result are demonstrated and discussed. Section 3 considers a model with a continuum of states. In particular, that section provides a sufficient condition (stated in terms of some properties of the distribution of the stochastic demand intercept) for this model to have a unique equilibrium. Section 4 concludes. Some of the proofs are relegated to an appendix.

\section{A Model with Two States}

\subsection{Model}

Consider a Cournot model with $n \geq 1$ firms producing a homogenous good. The firms are identical and indexed by $i \in\{1,2, \ldots, n\}$. Each one of them faces a linear inverse demand function $p(X)=\max \{0, \alpha-b X\}$, where $p$ is price, $X \equiv \sum_{i=1}^{n} x_{i}$ is industry output, $x_{i}$ is firm $i$ 's output, and $\alpha>0$ and $b>0$ are exogenous parameters. All firms have the same constant marginal cost technology, with marginal cost denoted $c>0$, and there is no fixed cost. 
The intercept of the demand function, $\alpha$, is unknown by the firms. The intercept is either "low," in which case $\alpha=a-\Delta$, or "high," in which case $\alpha=a+\Delta$, with $a>\Delta>0$ and $a>c$. Each one of the states of nature occurs with equal probability: $\operatorname{Pr}(\alpha=a-\Delta)=\operatorname{Pr}(\alpha=a+\Delta)=1 / 2$.

Each firm $i$ is risk neutral and maximizes its expected profits. Its choice variable is its own output, $x_{i} \geq 0$, which it chooses simultaneously with the other firms. I will confine attention to pure strategy Nash equilibria of this game.

\subsection{Analysis and Results}

The algebra of the model is worked out in the Appendix. Here I will just state the results and subsequently explain the logic behind them. First, however, we need some more terminology and notation.

Let us make the observation that the fact that the intercept of the inverse demand function is stochastic together with the non-negativity constraint on market price imply that the expected price schedule, $E\{p(X)\}$, has a kink. (To see this, the reader may want to draw a figure.) The kink is located at that level of industry output where the price schedule in a low-demand state meets the horizontal axis, ${ }^{10}(a-\Delta) / b \equiv X^{k i n k}$. I will say that if $X<X^{k i n k}$, then industry output is located left of the kink; and if $X^{k i n k}<X$, then industry output is located right of the kink.

Let the cut-off values $\Delta^{*}$ and $\Delta^{* *}$ be defined by

$$
\begin{aligned}
\Delta^{*} & \equiv \frac{(2-\sqrt{2}) a+(n+2 \sqrt{2}-3) c}{n+\sqrt{2}-1}, \\
\Delta^{* *} & \equiv \frac{2(\sqrt{2}-1) a+(n+3-2 \sqrt{2}) c}{n+1} .
\end{aligned}
$$

One can readily verify that $0<\Delta^{*}<\Delta^{* *}<a$ for $n \geq 2$, and $0<\Delta^{*}=\Delta^{* *}<a$ for $n=1$. Moreover, let the output levels $x_{L}^{*}$ and $x_{R}^{*}$ be defined by

$$
x_{L}^{*} \equiv \frac{a-c}{b(n+1)}, \quad x_{R}^{*} \equiv \frac{a+\Delta-2 c}{b(n+1)} .
$$

\footnotetext{
${ }^{10}$ Of course, the expected price schedule has a kink also at the point where it meets the horizontal axis. Throughout the paper, however, the word "kink" will refer to the kink on the downward sloping part of the expected price schedule.
} 


\section{Proposition 1.}

- For $\Delta \in\left(0, \Delta^{* *}\right)$ there is a unique pure strategy equilibrium in which each firm's output equals $x_{L}^{*}$. Industry output in this equilibrium is located left of the kink.

— For $\Delta \in\left(\Delta^{*}, a\right)$ there is a unique pure strategy equilibrium in which each firm's output equals $x_{R}^{*}$. Industry output in this equilibrium is located right of the kink.

- For $\Delta \in\left[\Delta^{*}, \Delta^{* *}\right]$ there are exactly two pure strategy equilibria. One is left of the kink with each firm's output equal to $x_{L}^{*}$, whereas the other is right of the kink with each firm's output equal to $x_{R}^{*}$.

Figure 1 depicts $\Delta^{*}$ and $\Delta^{* *}$ as (linear) functions of $c$ for the case where $n \geq 2$ (recall that $\Delta^{*}$ and $\Delta^{* *}$ coincide if $n=1$ ). We know from Proposition 1 that an equilibrium in which industry output is right of the kink exists above the graph of $\Delta^{*}$, and an equilibrium in which industry output is left of the kink exists beneath the graph of $\Delta^{* *}$. Thus, in the region between the two graphs (the shadowed area in the figure) an equilibrium left of the kink co-exists with an equilibrium right of the kink.

Clearly, the reason why this model gives rise to a multiplicity of equilibria is related to the non-negativity constraint and the kink that it implies. The crucial model feature, however, is not the existence of a kink per se, but the fact that the expected price schedule is convex in a region where it pays off for the firms to produce. It is well known from work on the Cournot model under complete information that there can exist multiple equilibria if the demand function is sufficiently convex. The reason why a convexity of demand has this effect is that it tends to create a strategic complementarity between a firm's own output and its competitors' output: the marginal gain in profits from increasing the own strategic variable is increasing in each of the competitors' strategic variables. ${ }^{11}$ As a consequence, a low-output equilibrium can exist simultaneously with a

\footnotetext{
${ }^{11}$ To see this, suppose inverse demand is known and given by $D(x+y)$, where $x$ is own output and $y$ is the competitors' joint output, and denote the cost function by $C(x)$. Then own profits are given by $\pi(x, y)=D(x+y) x-C(x)$. Differentiating $\pi$ twice, first with respect to $x$ and then with respect to $y$, one has $\pi_{12}^{\prime \prime}(x, y)=D^{\prime}(x+y)+x D^{\prime \prime}(x+y)$. This expression can be positive if $D^{\prime \prime}(x+y)$ is positive and sufficiently large, even if the demand function is downward-sloping.
} 
high-output equilibrium, since beliefs about the competitors' behavior become self-fulfilling.

In the model studied here, the requirement that price cannot be negative creates a convexity of the expected demand schedule, which again leads to a strategic complementarity and thus the possibility of multiple equilibria. In particular, although otherwise linear and downward sloping, firm $i$ 's best-response correspondence makes, because of the kink, one jump upwards. The jump occurs at an output level of the other firms that is just large enough to make it optimal for firm $i$ to produce such a large quantity itself that industry output locates right of the kink instead of left of it.

Figure 1 also tells us that as the number of firms in the market, $n$, increases, the intercept of the graphs of $\Delta^{*}$ and $\Delta^{* *}$ move downwards and, in the limit, both straight lines approach the 45-degree line. Hence, as the market approaches perfect competition, the scope for multiple equilibria in this model vanishes.

Let us now ask the question how the fact that the firms have incomplete information affects expected profits and expected total surplus. The model that I will use as a benchmark for comparison is identical to the one described in Section 2.1, except that in the benchmark all firms know the realization of the demand shock when they make their output decisions. I will make the comparison from an ex ante perspective.

When the value of the demand intercept, $\alpha \in\{a-\Delta, a+\Delta\}$, is common knowledge, we know from standard calculations that there is a unique equilibrium in which each firm produces $x_{B} \equiv \max \{0,(\alpha-c) /[b(n+1)]\}$ (the subscript $B$ is short for "benchmark"). Thus, in a high-demand state the output level $x_{B}$ is always strictly positive, whereas in a low-demand state $x_{B}=0$ for $\Delta \leq a-c$. Denote by $\pi_{B}(\alpha)$ and $C S_{B}(\alpha)$ a firm's profits respectively the consumer surplus in the benchmark model, given a realization of the demand intercept $\alpha$. We have

$$
\pi_{B}(\alpha)=\left(\alpha-c-b n x_{B}\right) x_{B}, \quad C S_{B}(\alpha)=\frac{b\left(n x_{B}\right)^{2}}{2} .
$$

Total surplus (or "welfare") in the benchmark model, given a realization of $\alpha$, then equals $W_{B}(\alpha)=C S_{B}(\alpha)+n \pi_{B}(\alpha)$. The expected profit and expected total surplus, $E \pi_{B}$ and $E W_{B}$, are defined as the expected values of $\pi_{B}(\alpha)$ and $W_{B}(\alpha)$, given that the probability of each state is $1 / 2$. 
Now let us return to the incomplete information model. In an equilibrium left of the kink, the non-negativity constraint on price is never binding. Hence, results that are novel relative to the existing literature can be expected to be found only in an equilibrium right of the kink. Therefore, I will make the profit and total surplus comparison only for such an equilibrium of the incomplete information model.

Accordingly, assume that $\Delta \in\left(\Delta^{*}, a\right)$ and that an equilibrium right of the kink is played. Denote by $\pi^{*}(\alpha)$ and $C S^{*}(\alpha)$ a firm's profits respectively the consumer surplus in the incomplete information model, given a realization of the demand intercept $\alpha$. In a low-demand state, market price is zero. Hence, $\pi^{*}(a-\Delta)=-c x_{R}^{*}$ (i.e., the firm has no revenues, so its profits equal minus its production costs). In a high-demand state, $\pi^{*}(\alpha)$ is defined analogously to $\pi_{B}(\alpha)$ in (4), but with $x_{R}^{*}$ substituted for $x_{B}$. Similarly, since market price is zero in a low-demand state, I say that $C S^{*}(a-\Delta)$ is given by the whole area beneath the demand schedule, $C S^{*}(a-\Delta)=(a-\Delta)^{2} / 2 b$ (i.e., all the goods that are produced are handed over to the consumers free of charge). In a high-demand state, $C S^{*}(\alpha)$ is defined analogously to $C S_{B}(\alpha)$ in (4), but with $x_{R}^{*}$ substituted for $x_{B}$. Total surplus, given a realization of $\alpha$, is defined by $W^{*}(\alpha)=C S^{*}(\alpha)+n \pi^{*}(\alpha)$. Finally, the expected profit and expected total surplus, $E \pi^{*}$ and $E W^{*}$, are defined as the expected values of $\pi^{*}(\alpha)$ and $W^{*}(\alpha)$, given that the probability of each state is $1 / 2$.

The following result is proven in the Appendix.

Proposition 2. Suppose $\Delta \in\left(\Delta^{*}, a\right)$ and that an equilibrium right of the kink is played in the incomplete information model. Then:

a) Expected profits are always strictly higher under complete information than under incomplete information (i.e., $E \pi^{*}>E \pi_{B}$ ).

b) Expected total surplus under incomplete information is (strictly) higher than expected social welfare under complete information (i.e., $\left.E W^{*}>E W_{B}\right)$ if and only if $\Delta<\varphi(a, c, n)$, where

$$
\varphi(a, c, n) \equiv a-\frac{2 a-c}{1+\sqrt{1+\frac{2 a-c}{2 n(n+2) c}}} .
$$


Part a) of Proposition 2 is quite intuitive and in line with what we know from the existing literature. Part b) is illustrated in Figure 2. This figure shows (the relevant part of) the graph of the function $\varphi$, in the same $(\Delta, c)$ space as in Figure 1. In the (non-empty) subset of the parameter space beneath this graph and above the graph of $\Delta^{*}$ (the shadowed area in the figure), an equilibrium right of the kink exists in the model with incomplete information and expected total surplus in that equilibrium is higher than in the benchmark model where the firms do know demand.

The reason why expected total surplus can be lower when the firms are informed is that a firm that does not know demand is bolder (or more aggressive) when choosing its output: it chooses a quantity that is large relative to what it would have chosen on average if it had known demand. The reason for this, in turn, is that if the firm chooses a relatively large quantity and demand turns out to be low, its losses will, because of the non-negativity constraint on price, be limited to its production costs.

Given this logic, we should expect the "boldness effect" to be stronger the lower is the marginal/average cost. Indeed, provided an equilibrium right of the kink exists, $\varphi_{2}^{\prime}(a, c, n)<0$. Moreover, $\lim _{c \rightarrow 0} \varphi(a, c, n)=a$, which means that in the limit, as the constant marginal cost approaches zero, informed firms are detrimental to expected total surplus for all $\Delta \in\left(\Delta^{*}, a\right)$, i.e., whenever an equilibrium right of the kink exists. We also have that $\varphi_{3}^{\prime}(a, c, n)<0$ : stiffer competition decreases the cut-off value below which $\Delta$ must be for informed firms to be bad for expected total surplus. Indeed, in the limit as $n$ approaches infinity, informed firms are never detrimental to expected total surplus.

To see the significance of Proposition 2b, let us briefly review what received theory has to say about the welfare effects of better informed firms in an oligopoly (or monopoly) market. Vives (1984) studies a linear-quadratic duopoly model with uncertainty about the intercept of the demand function. In one version of his model he assumes Cournot competition, whereas in another there is Bertrand competition. Vives does not impose any non-negativity constraint on the variable that is not chosen by the firms (i.e., in the Cournot model price can be negative and in the Bertrand model output can be negative). He computes the social value (i.e., the difference in expected total surplus) of the firms' 
having access to more information and shows that there is a strict dichotomy between the Cournot and Bertrand models: the social value of information is positive under Cournot and negative under Bertrand competition. ${ }^{12}$

How can we understand this dichotomy? One might have expected more information to be socially beneficial under both Cournot and Bertrand competition, since it should help the firms to tailor their decisions to actual demand, thus facilitating the exploitation of gains from trade and making the cake to be shared between the firms and the consumers bigger. Of course, however, the firms do not care about the size of this cake per se but about their share of it. Still, it turns out that when the firms are quantity setters, then a firm's objective of maximizing the share of the cake is relatively well aligned with the social goal of maximizing the cake size; for price setters, though, these goals are less well aligned. This difference between quantity setting and price setting is due to the facts that: (1) socially "good behavior" on the part of the firms (i.e., their choosing large quantities respectively low prices) is more valuable in a high-demand state than in a low-demand state (basically because the traded quantity is larger in a high-demand state); and (2) a quantity setter who gets access to information responds by producing more in a high-demand state and less in a low-demand state, whereas a price setter responds by choosing a high price in a high-demand state and a low price in a low-demand state. ${ }^{13}$

The effect discussed in the previous paragraph is present also in the model studied in the current paper - indeed, this is why expected total surplus is greater with informed than with uninformed firms whenever $\Delta>\varphi(a, c, n)$. In the model studied here, however, there is a non-negativity constraint on price, which gives rise to the boldness effect discussed earlier. As a result, whether information is good or bad does not depend only on whether the firms choose price or quantity, but also on the strength of the boldness effect. In particular, when the marginal cost parameter is relatively low, which makes the boldness effect strong, information is bad also under Cournot competition.

Although the case with Bertrand competition (with differentiated goods) is

\footnotetext{
${ }^{12}$ For discussions of the welfare effects of information sharing, see also, for example, Clarke (1983), Novshek and Sonnenschein (1982), Sakai and Yamato (1989), Shapiro (1986), and Vives (1990).

${ }^{13}$ Kühn and Vives (1995) discuss this intuition at length and also illustrate it in figures. See also Weitzman (1974) for an early analysis of the difference between price and quantity setting under uncertainty.
} 
not analyzed in the present paper, it is fairly straightforward to understand how the logic would work in such a model: a non-negativity constraint on quantity would make it more tempting for firms to choose a high price. Thus, in a model where firms choose prices and there is a non-negativity constraint on quantity, the boldness effect would tend to make uninformed firms harmful to consumers, since it creates an incentive to set a higher price. Also in such a model, the boldness effect would be stronger when the production costs are relatively low. Hence, one should expect that for sufficiently low values of the marginal cost parameter, the boldness effect would be stronger than the effect present in Vives (1984) also under Bertrand competition, with the result being that, for a subset of the parameter space, informed firms is good for expected total surplus.

In sum, the strict dichotomy between Cournot and Bertrand is broken once we introduce the non-negativity constraint: depending on the parameters, information can be either good or bad in each one of the two models. In particular, the traditional welfare result in the Cournot model (information is good) is reversed for sufficiently low values of the marginal cost parameter (for then the boldness effect is relatively strong), and we should expect the analogous result in the Bertrand model.

\section{A Model with a Continuum of States}

\subsection{Model}

In this section I will assume that $\alpha$, the intercept of the inverse demand function, can take on any value in the interval $[0, \bar{\alpha}]$, where $\bar{\alpha}>0$. (We can also have $\alpha \in[0, \infty)$, a case which corresponds to $\bar{\alpha}=\infty$ in the text and the formulas below.) More precisely, although the intercept $\alpha$ is unknown by the firms, they know that it is distributed according to the cumulative distribution function $F$, which is three times continuously differentiable. Its associated density function is denoted $f$ and is strictly positive on $(0, \bar{\alpha})$. Moreover, the expected value of $\alpha$ is assumed to exceed the constant marginal cost, $E(\alpha) \equiv \int_{0}^{\bar{\alpha}} a f(a) d a>c$. All other parts of the model are exactly as in the two-state model described in Section 2.1. I will again confine attention to pure strategy Nash equilibria. 


\subsection{Analysis and Results}

Since market price is zero for any $\alpha \leq b X$, firm $i$ 's expected profits can be written as $E \pi_{i}=(P(X)-c) x_{i}$, where

$$
P(X) \equiv \max \left\{0, \int_{b X}^{\bar{\alpha}}(a-b X) f(a) d a\right\} .
$$

Thus, our incomplete information model is strategically equivalent to a symmetric Cournot model with complete information and with inverse demand function $P(X)$, where $P(X)$ is continuously differentiable and with $P^{\prime}(X)<0$ in the relevant output interval. From the existing literature we know several things about such a model. In particular, the results of Amir and Lambson (2000) tell us the following. 14

Lemma 1. A pure strategy Nash equilibrium exists. In any such equilibrium, all firms produce the same quantity, $x^{*}$. Moreover, $x^{*}>0$ and equilibrium industry output, $X^{*} \equiv n x^{*}$, satisfies

$$
\int_{b X^{*}}^{\bar{\alpha}} a f(a) d a-c=\frac{(n+1) b X^{*}}{n}\left[1-F\left(b X^{*}\right)\right] .
$$

Proof. From Theorem 2.1 of Amir and Lambson (2000) we know that, under conditions that are satisfied in our setting, our model has at least one symmetric equilibrium and no asymmetric equilibria. Moreover, by differentiating $E \pi_{i}$ with respect to $x_{i}$ we have

$$
\frac{\partial E \pi_{i}}{\partial x_{i}}=\int_{b X}^{\bar{\alpha}} a f(a) d a-b\left(x_{i}+X\right)[1-F(b X)]-c .
$$

Evaluating this expression at $x_{i}=0$ and $X=0$ yields $\left.\frac{\partial E \pi_{i}}{\partial x_{i}}\right|_{x_{i}=0, X=0}=E(\alpha)-c$, which is strictly positive by assumption. Hence, all firms cannot produce zero output in a Nash equilibrium. It follows that all firms must produce the same positive quantity and that this satisfies $\partial E \pi_{i} / \partial x_{i}=0$, which rewritten yields (6).

\subsubsection{A Sufficient Condition for Uniqueness}

Let us now ask under what circumstances there is a unique pure strategy Nash equilibrium. I will derive a sufficient condition for this, stated in terms of some

${ }^{14}$ The symmetry and existence results below actually hold for any convex cost function. In order to prove the results reported on later in this section, however, I need the constant marginal cost assumption, which is why I impose it already from the outset. 
properties of the distribution $F$, under the following assumption: ${ }^{15}$

Assumption 1. $f(0)<[E(\alpha)-c]^{-1}$.

Rewriting firm $i$ 's first-order condition $\partial E \pi_{i} / \partial x_{i}=0$ (using (7)) one has

$$
x_{i}=\frac{\int_{b X}^{\bar{\alpha}} a f(a) d a-c}{b[1-F(b X)]}-X \equiv R(X) .
$$

The function $R(X)$ defined in (8) is sometimes called an inclusive best-response function. It differs from a standard best-response function in that its argument is the sum of all firms' output, including firm $i$ 's own. ${ }^{16}$ Although it may - because of this reason - be hard to interpret, the inclusive best-response function will prove very convenient to work with. Under our assumptions about $F, R$ is continuous and differentiable with respect to $X$ for all $X \in(0, \bar{\alpha} / b)$. Note that differentiating $R(X)$ yields

$$
R^{\prime}(X)=b R(X) h(b X)-1,
$$

where $h(X) \equiv f(X) /[1-F(X)]$ is the hazard rate of $F$.

Under Assumption 1, if there exist more than one Nash equilibrium, the graph of $R(X)$ must look something like the one that is depicted in Figure 3. More precisely, since the graph must cross the straight line $R(X)=X / n$ at least twice and it begins above it and ends below it ${ }^{17}$ there must exist two distinct $X^{\prime}$ 's, say $X^{\prime}$ and $X^{\prime \prime}$, with $0<X^{\prime}<X^{\prime \prime}<\bar{\alpha} / b$, such that $R^{\prime}\left(X^{\prime}\right)=R^{\prime}\left(X^{\prime \prime}\right)=0$, $R^{\prime \prime}\left(X^{\prime}\right)>0$, and $R^{\prime \prime}\left(X^{\prime \prime}\right)<0$.

What restrictions do these conditions impose on the distribution $F$ ? To see this, differentiate the expression for $R^{\prime}$ in (9):

$$
R^{\prime \prime}(X)=b\left[R^{\prime}(X) h(b X)+b R(X) h^{\prime}(b X)\right] .
$$

Hence, since $R^{\prime}\left(X^{\prime}\right)=R^{\prime}\left(X^{\prime \prime}\right)=0$,

$$
R^{\prime \prime}\left(X^{\prime}\right)=\frac{b h^{\prime}\left(b X^{\prime}\right)}{h\left(b X^{\prime}\right)} \text { and } R^{\prime \prime}\left(X^{\prime \prime}\right)=\frac{b h^{\prime}\left(b X^{\prime \prime}\right)}{h\left(b X^{\prime \prime}\right)} .
$$

\footnotetext{
${ }^{15}$ Assumption 1 is obviously satisfied for any distribution for which $f(0)=0$, such as a log-normal. One can verify that it holds also for an exponential distribution, for a uniform distribution on $[0, \bar{\alpha}]$, and for the following "triangular" distribution: $f(a)=2(\bar{\alpha}-a) / \bar{\alpha}^{2}$ for $a \in[0, \bar{\alpha}]$ and $f(a)=0$ otherwise (obviously, here $\bar{\alpha}$ must be finite).

${ }^{16}$ The inclusive best-response function was first used by Selten (1970) and then later, but independently, by Novshek (1985) to prove existence results.

${ }^{17}$ Moreover, Assumption 1 guarantees that $R^{\prime}(0)<0$.
} 
This means that $h^{\prime}\left(b X^{\prime}\right)>0$ whereas $h^{\prime}\left(b X^{\prime \prime}\right)<0$.

The above analysis in conjunction with Lemma 1 yield the following proposition.

Proposition 3. Suppose that Assumption 1 is satisfied. Moreover, suppose that $F$ is such that its hazard rate is either (i) monotone or (ii) changing sign exactly once and it is first decreasing and then increasing. Then there exists exactly one pure strategy Nash equilibrium.

Most standard distribution functions have a monotone hazard rate, and it is an often-made assumption in many areas of economic theory. Of course, however, this does not necessarily mean that the condition is satisfied empirically. I will leave for future work the task of exploring in greater detail what kind of distributions that do give rise to multiple equilibria. Let us note, though, that the two-state distribution that was assumed in Section 2 could be approximated with a continuous-state two-hump distribution that satisfies all the differentiability and full-support assumptions made in this section, and which would therefore also give rise to two co-existing equilibria. ${ }^{18}$

What is the role of Assumption 1 in Proposition 3? As already mentioned, this assumption guarantees that the graph of $R(X)$ has a negative slope at $X=0$, which is needed for the argument in the proof of Proposition 3 to be valid. Another way of understanding Assumption 1 is to note that it equivalently can be written as

$$
\lim _{X \rightarrow 0} \frac{\partial^{2} \log (P(X)-c)}{\partial X^{2}}<0 .
$$

That is, Assumption 1 guarantees that $(P(X)-c)$ is log-concave for $X$ close to zero. In his analysis of a complete information Cournot duopoly model with constant marginal costs, Amir (1996, Theorem 2.7), too, proves a uniqueness result under the assumption that $(P(X)-c)$ is log-concave, although for $X$ 's lying in another region (namely, between the monopoly output and the output associated with marginal cost pricing). Of course, Amir's analysis is not a substitute for Proposition 3, but it suggests that Assumption 1 might not be needed for the proposition to hold. (I leave for future work any attempts to strengthen the result reported in Proposition 3.)

\footnotetext{
${ }^{18}$ Thus, a conjecture would be that markets in which demand is likely to be either relatively low or relatively high give rise to a multiplicity of equilibria.
} 


\subsubsection{The Value of Information}

Let us now turn to the question how the fact that the firms have incomplete information affects expected firm profits and expected consumer surplus. As in the previous section, the benchmark with which I will compare is a model where all firms know the realization of $\alpha$ when making their output decisions. Using the same notation as in that section, each firm's output in the benchmark equals $x_{B} \equiv \max \{0,(\alpha-c) /[b(n+1)]\}$. Thus, output is zero for any realization of the demand intercept such that $\alpha \leq c$. Expected firm profits and expected consumer surplus in the benchmark can be written as (cf. (4))

$$
E \pi_{B}=\frac{\int_{c}^{\bar{\alpha}}(a-c)^{2} f(a) d a}{b(n+1)^{2}}, \quad E C S_{B}=\frac{n^{2} \int_{c}^{\bar{\alpha}}(a-c)^{2} f(a) d a}{2 b(n+1)^{2}} .
$$

In an equilibrium of the model with incomplete information, expected firm profits in equilibrium are given by

$$
E \pi^{*}=\frac{X^{*}}{n}\left[\int_{b X^{*}}^{\bar{\alpha}}\left(a-b X^{*}\right) f(a) d a-c\right]=\frac{b\left(X^{*}\right)^{2}}{n^{2}}\left[1-F\left(b X^{*}\right)\right]
$$

(the second equality follows from (6)). Expected consumer surplus in the model with incomplete information is given by

$$
E C S^{*}=\frac{b\left(X^{*}\right)^{2}}{2}\left[1-F\left(b X^{*}\right)\right]+\frac{1}{2 b} \int_{0}^{b X^{*}} a^{2} f(a) d a .
$$

Let us write $\Delta \pi \equiv E \pi_{B}-E \pi^{*}$ and $\Delta C S \equiv E C S_{B}-E C S^{*}$. We have immediately from (10)-(12) that the following relationship holds:

$$
\Delta C S=\frac{n^{2}}{b} \Delta \pi-\frac{1}{2 b} \int_{0}^{b X^{*}} a^{2} f(a) d a .
$$

That is, if the consumers gain from informed firms, so do the firms themselves. The following proposition tells us that the consumers gain if the marginal cost is large enough.

Proposition 4. For c sufficiently close to $E(a), \Delta C S>0$.

Further general results seem hard to obtain. Let us instead consider the following example. 
Example 1: Uniform Distribution. Assume $F(a)=a / \bar{\alpha}$ and $f(a)=1 / \bar{\alpha}$ for $a \in[0, \bar{\alpha}]$. Using (6), one can then show that

$$
X^{*}=\frac{n(\bar{\alpha}-2 c)}{b\left(n+1+\sqrt{1+\frac{2 n(n+2) c}{\bar{\alpha}}}\right)} .
$$

Furthermore, by using this expression for $X^{*}$ together with (10) and (12) and carrying out some algebra, one can show that $\Delta C S>0$ as

$$
\frac{\left(1-\frac{c}{\bar{\alpha}}\right)^{3}}{\left(1-\frac{2 c}{\bar{\alpha}}\right)^{2}}>\frac{(n+1)^{2}\left[3\left(1+\sqrt{1+\frac{2 n(n+2) c}{\bar{\alpha}}}\right)+4 n \frac{c}{\bar{\alpha}}+n\right]}{\left(n+1+\sqrt{1+\frac{2 n(n+2) c}{\bar{\alpha}}}\right)^{3}} .
$$

One can easily verify that, for any finite $n$, the inequality in (14) is satisfied for $c / \bar{\alpha}$ close to $1 / 2$, whereas the reverse equality holds for $c / \bar{\alpha}$ close to 0 . That is, for values of $c$ sufficiently small, the expected consumer surplus is greater when the firms do not know demand than when they do. In the limit, however, as $n$ approaches infinity, the right-hand side of (14) approaches $\left(3 \sqrt{\frac{2 c}{\bar{\alpha}}}+\frac{4 c}{\bar{\alpha}}+1\right) /\left(1+\sqrt{\frac{2 c}{\bar{\alpha}}}\right)^{3}$, which can be shown to be strictly smaller than the left-hand side (for all $c / \bar{\alpha}$ ).

\section{Concluding Remarks}

In this paper I have argued that ignoring the non-negativity constraint on price when modeling uncertainty in oligopolistic (or monopolistic) markets may make us overlook important economic insights. In particular, I showed that taking the non-negativity constraint explicitly into account in a simple Cournot model with demand uncertainty can lead to (1) a multiplicity of equilibria and to (2) the phenomenon that expected total surplus is larger when the firms do not know the demand than when they do.

Observation (2) has been made before by Malueg and Tsutsui (1998), although only by means of a numerical duopoly example. In the present paper, thanks to the fact that here information is symmetric (but incomplete), I could derive more general results. These suggest that the tendency for informed firms to be bad for welfare is stronger when marginal/average cost is low and that providing the firms with more information is always good if the number of firms 
in the market is sufficiently large. Observation (1) was complemented by a result showing that if the distribution of the unknown demand intercept has a monotone hazard rate and if another, rather weak, assumption is satisfied, then uniqueness of equilibrium is guaranteed.

The arguments of the paper are relevant also for price competition (see the end of Section 2.2) and for uncertainty about market features other than the demand intercept. Suppose, for example, that there are at least two firms in a Cournot market and that each firm has private information about its own (constant) marginal cost, thus making its output decision contingent on this information. Then, from the point of view of an individual firm, aggregate output will be stochastic and the non-negativity constraint on price will, at least for some possible output choices, be binding with positive probability. In such a model the non-negativity constraint should play a role that is very similar to the one explored in the models of the present paper. The same is true for anything else that is private information to a firm and which affects its output choice. It could also be that the number of firms in the market is unknown to an individual firm, which again would make aggregate output stochastic from the point of view of that firm. Examining these and other alternative models in greater detail could yield further insights.

\section{Appendix}

Proof of Proposition 1. Let us first look for equilibria left of the kink, i.e., where $X^{*}<X^{k i n k}(=(a-\Delta) / b)$. It is straightforward to verify that in such an equilibrium, given that it exists, all firms produce the same quantity, namely $x_{L}^{*}$ as defined in (3). Now consider firm $i$ 's incentive to deviate to some $x_{i}$ such that $x_{i}+(n-1) x_{L}^{*} \geq(a-\Delta) / b$ or, rewriting, to some $x_{i}$ such that

$$
x_{i} \geq \frac{a-\Delta}{b}-(n-1) x_{L}^{*}=\frac{2 a-(n+1) \Delta+(n-1) c}{b(n+1)} \equiv A(\Delta) .
$$

If deviating to such an $x_{i}$, firm $i$ 's expected profits are given by

$$
\left(\frac{a+\Delta-b x_{i}-b(n-1) x_{L}^{*}}{2}-c\right) x_{i}=\left(\frac{2 a+(n+1) \Delta-(n+3) c}{2(n+1)}-\frac{b}{2} x_{i}\right) x_{i} .
$$


Maximizing this expression with respect to $x_{i}$ subject to $x_{i} \geq A(\Delta)$ yields an optimal $\widehat{x}$ given by

$$
\widehat{x}=\left\{\begin{array}{cl}
A(\Delta) & \text { if } \Delta \leq \frac{2 a+(3 n+1) c}{3(n+1)} \\
\frac{2 a+(n+1) \Delta-(n+3) c}{2 b(n+1)} & \text { if } \Delta>\frac{2 a+(3 n+1) c}{3(n+1)} .
\end{array}\right.
$$

Clearly, when $\Delta$ is such that the constraint $x_{i} \geq A(\Delta)$ is binding, then firm $i$ does not have an incentive to deviate. Consider the case where the constraint is not binding. Compute firm $i$ 's expected profit if not deviating and if deviating:

$$
\begin{gathered}
\pi_{i}(\text { not deviating })=\frac{(a-c)^{2}}{b(n+1)^{2}}, \\
\pi_{i}(\text { deviating })=\left(b \widehat{x}-\frac{b}{2} \widehat{x}\right) \widehat{x}=\frac{[2 a+(n+1) \Delta-(n+3) c]^{2}}{8 b(n+1)^{2}}
\end{gathered}
$$

(the last two equalities make use of (15) and (16)). It is a straightforward exercise to verify that $\pi_{i}$ (deviating) is monotone increasing in $\Delta$ for all $\Delta>$ $[2 a+(3 n+1) c] / 3(n+1)$. Moreover, aggregate output in an equilibrium left of the kink equals $n x_{L}^{*}$, so we will indeed have an equilibrium left of the kink if and only if $n x_{L}^{*}<X^{k i n k}$ or, rewriting, $\Delta<(a+n c) /(n+1)$. Evaluating $\pi_{i}$ (deviating) at $\Delta=(a+n c) /(n+1)$ yields

$$
\left.\pi_{i}(\text { deviating })\right|_{\Delta=\frac{a+n c}{n+1}}=\frac{9(a-c)^{2}}{8 b(n+1)^{2}}>\pi_{i}(\text { not deviating }) .
$$

Thus, there exists a unique $\Delta_{A}$, satisfying

$$
\frac{2 a+(3 n+1) c}{3(n+1)}<\Delta_{A}<\frac{a+n c}{n+1}
$$

and

$$
\frac{(a-c)^{2}}{b(n+1)^{2}}=\frac{\left[2 a+(n+1) \Delta_{A}-(n+3) c\right]^{2}}{8 b(n+1)^{2}}
$$

such that firm $i$ will not have an incentive to deviate if and only if $\Delta \leq \Delta_{A}$. The equality in (17) has a unique root in the relevant interval which is given by $\Delta_{A}=\Delta^{* *}$, where $\Delta^{* *}$ is defined in (2).

Now let us look for equilibria right of the kink, i.e., where $X>X^{k i n k}$. It is straightforward to verify that in such an equilibrium, given that it exists, all firms produce the same quantity, namely $x_{R}^{*}$ as defined in (3). This output is non-negative only if $\Delta \geq 2 c-a$, which thus is a necessary condition for an 
equilibrium right of the kink to exist. Consider firm $i$ 's incentive to deviate to some $x_{i}$ such that $x_{i}+(n-1) x_{R}^{*} \leq X^{k i n k}$ or, rewriting, to some $x_{i}$ such that

$$
x_{i} \leq \frac{a-\Delta}{b}-(n-1) x_{R}^{*}=\frac{2[a-n \Delta+(n-1) c]}{b(n+1)} \equiv B(\Delta) .
$$

Note that $B(\Delta)<0$ if $\Delta>[a+(n-1) c] / n$, in which case firm $i$ is unable to move industry output left of the kink. Hence, suppose that $\Delta$ is small enough so that $B(\Delta) \geq 0$. Now, if deviating to an $x_{i} \in[0, B(\Delta)]$, firm $i$ 's expected profits are given by

$$
\left(a-b x_{i}-b(n-1) x_{R}^{*}-c\right) x_{i}=\left(\frac{2 a-(n-1) \Delta+(n-3) c}{n+1}-b x_{i}\right) x_{i} .
$$

Maximizing this expression with respect to $x_{i}$ subject to $x_{i} \leq B(\Delta)$ (the constraint $x_{i} \geq 0$ will not be binding when $B(\Delta) \geq 0$ ) yields an optimal $\widehat{x}$ given by

$$
\widetilde{x}=\left\{\begin{array}{cl}
\frac{2 a-(n-1) \Delta+(n-3) c}{2 b(n+1)} & \text { if } \Delta \leq \frac{2 a+(3 n-1) c}{3 n+1} \\
B(\Delta) & \text { if } \Delta>\frac{2 a+(3 n-1) c}{3 n+1} .
\end{array}\right.
$$

Clearly, when $\Delta$ is such that the constraint $x_{i} \leq B(\Delta)$ is binding, then firm $i$ does not have an incentive to deviate. Consider the case where the constraint is not binding. Calculate firm $i$ 's profit if not deviating and if deviating:

$$
\pi_{i}^{N o t D e v}=\frac{(a+\Delta-2 c)^{2}}{2 b(n+1)^{2}}, \quad \pi_{i}^{D e v}=(2 b \widetilde{x}-b \widetilde{x}) \widetilde{x}=\frac{[2 a-(n-1) \Delta+(n-3) c]^{2}}{4 b(n+1)^{2}}
$$

(the last two equalities make use of (18) and (19)). Given that $x_{R}^{*} \geq 0$ (so that $\Delta \geq 2 c-a), \pi_{i}^{\text {NotDev }}$ is monotone increasing in $\Delta$, and one can verify that $\pi_{i}^{\text {Dev }}$ is monotone decreasing in $\Delta$ provided that $B(\Delta) \geq 0$. Moreover, aggregate output in an equilibrium right of the kink equals $n x_{R}^{*}$, so we will indeed have an equilibrium right of the kink if $n x_{R}^{*}>X^{k i n k}$ or, rewriting, $\Delta>(a+2 n c) /(2 n+1)$. Evaluating the above two expressions at $\Delta=(a+2 n c) /(2 n+1)$, we have

$$
\left.\pi_{i}^{\text {NotDev }}\right|_{\Delta=\frac{a+2 n c}{2 n+1}}=\frac{2(a-c)^{2}}{b(2 n+1)^{2}},\left.\quad \pi_{i}^{D e v}\right|_{\Delta=\frac{a+2 n c}{2 n+1}}=\frac{9(a-c)^{2}}{4 b(2 n+1)^{2}} .
$$

Hence, for $\Delta=\frac{a+2 n c}{2 n+1}, \pi_{i}^{D e v}>\pi_{i}^{\text {NotDev }}$. This means that there exists a unique $\Delta_{B}$, satisfying

$$
\frac{a+2 n c}{2 n+1}<\Delta_{B}<\frac{2 a+(3 n-1) c}{3 n+1}
$$


and

$$
\frac{\left(a+\Delta_{B}-2 c\right)^{2}}{2 b(n+1)^{2}}=\frac{\left[2 a-(n-1) \Delta_{B}+(n-3) c\right]^{2}}{4 b(n+1)^{2}},
$$

such that firm $i$ will not have an incentive to deviate if and only if $\Delta \geq \Delta_{B}$. The equality in (20) has a unique root in the relevant interval which is given by $\Delta_{B}=\Delta^{*}$, where $\Delta^{*}$ is defined in (1).

Proof of Proposition 2. The proof makes use of Table A1, the entries of which can be calculated by using the definitions and formulas provided in Section 2. Let us first prove part a) of the proposition. For the case $\Delta>a-c$ it follows immediately from Table A1 that $E \pi_{B}>E \pi^{*}$. Next consider the case $\Delta \leq a-c$. From Table A1 we have that $E \pi_{B}>E \pi^{*} \Leftrightarrow 2\left[(a-c)^{2}+\Delta^{2}\right]>(a+\Delta-2 c)^{2}$, which can be rewritten as

$$
[\Delta-(a-2 c)]^{2}>2\left[(a-2 c)^{2}-(a-c)^{2}\right]=-2 c(2 a-3 c) .
$$

Recall that $\Delta>\Delta^{*}$ implies $\Delta>c$. Thus, a necessary condition for having $\Delta \leq a-c$ is that $a>2 c$. But this means that the right-hand side of the inquality above is strictly negative, so the inequality must always hold.

\begin{tabular}{|c|c|c|c|}
\hline & C. I.: $\Delta \leq a-c$ & C. I.: $\Delta>a-c$ & Incompl. Info. \\
\hline$\pi(a-\Delta)$ & $\frac{(a-\Delta-c)^{2}}{b(n+1)^{2}}$ & 0 & $-c x_{R}^{*}$ \\
\hline$\pi(a+\Delta)$ & $\frac{(a+\Delta-c)^{2}}{b(n+1)^{2}}$ & $\frac{(a+\Delta-c)^{2}}{b(n+1)^{2}}$ & $\frac{[a+\Delta+(n-1) c](a+\Delta-2 c)}{b(n+1)^{2}}$ \\
\hline$E \pi$ & $\frac{(a-c)^{2}+\Delta^{2}}{b(n+1)^{2}}$ & $\frac{(a+\Delta-c)^{2}}{2 b(n+1)^{2}}$ & $\frac{(a+\Delta-2 c)^{2}}{2 b(n+1)^{2}}$ \\
\hline$C S(a-\Delta)$ & $\frac{n^{2}(a-\Delta-\Delta)^{2}}{2 b(n+1)^{2}}$ & 0 & $\frac{n^{2}(a+\Delta-2 c)^{2}}{2 b(n+1)^{2}}$ \\
\hline$C S(a+\Delta)$ & $\frac{n^{2}(a+\Delta-c)^{2}}{2 b(n+1)^{2}}$ & $\frac{n^{2}(a+\Delta-c)^{2}}{2 b(n+1)^{2}}$ & $\frac{n^{2}}{4 b(a+\Delta-c)^{2}}$ \\
\hline$E C S$ & $\frac{n^{2}\left[(a-c)^{2}+\Delta^{2}\right]}{2 b(n+1)^{2}}$ & $\frac{n^{2}(n+1)^{2}}{4 b(n+1)^{2}}$ & $\frac{(n+1)^{2}(a-\Delta)^{2}+n^{2}(a+\Delta)^{2}}{4 b(n+1)^{2}}$ \\
\hline$E W$ & $\frac{n(n+2)\left[(a-)^{2}+\Delta^{2}\right]}{2 b(n+1)^{2}}$ & $\frac{n(n+2)(a+\Delta-c)^{2}}{4 b(n+1)^{2}}$ & $\frac{(n+1)^{2}(a-\Delta)^{2}+n(n+2)(a+\Delta-2 c)^{2}}{4 b(n+1)^{2}}$ \\
\hline
\end{tabular}

Table A1: Profits, consumer surplus, and welfare under complete and incomplete information. Columns two and three concern the benchmark model with complete information, whereas the last column refers to the incomplete information model. The notation in the first column is for simplicity written without the subindex " $B$ " or the superindex "*". Thus, $\pi(a-\Delta)$, for example, should be understood as either $\pi_{B}(a-\Delta)$ or $\pi^{*}(a-\Delta)$, depending on which column one is reading from. 
Let us now prove b). First consider the case $\Delta>a-c$. Here, using Table A1 and simplifying, the inequality $E W^{*}<E W_{B}$ can be written as $\lambda(a, c, \Delta, n)>$ 0 , where $\lambda(a, c, \Delta, n) \equiv n(n+2) c\left[2(a+\Delta)-3 c^{2}\right]-(n+1)^{2}(a-\Delta)^{2}$. The function $\lambda$ is strictly increasing in $\Delta$. Recall that a necessary condition for an equilibrium right of the kink to exist is that $\Delta>c$. Hence, in order to show that $E W^{*}<E W_{B}$ for the relevant parameters (i.e., for all $\Delta>\max \{a-c, c\}$ ), it suffices to show that: for all $a \geq 2 c,\left.\lambda(a, c, \Delta, n)\right|_{\Delta=a-c}>0$; and for all $a \in(c, 2 c),\left.\lambda(a, c, \Delta, n)\right|_{\Delta=c}>0$. We have $\left.\lambda(a, c, \Delta, n)\right|_{\Delta=a-c}=4 n(n+2) a c-$ $\left(6 n^{2}+12 n+1\right) c^{2}$, which is indeed strictly positive for all $a \geq 2 c$. We also have $\left.\lambda(a, c, \Delta, n)\right|_{\Delta=c}=n(n+2) c(2 a-c)-(n+1)^{2}(a-c)^{2}$, which is concave in $a$ and strictly positive evaluated at $a=c$ and $a=2 c$. Hence, $\left.\lambda(a, c, \Delta, n)\right|_{\Delta=c}>0$ for all $a \in(c, 2 c)$.

It remains to consider the case $\Delta \leq a-c$. Using Table A1 and simplifying, $E W_{B}<E W^{*}$ can be written as $n(n+2)\left\{2\left[(a-c)^{2}+\Delta^{2}\right]-(a+\Delta-2 c)^{2}\right\}<$ $(n+1)^{2}(a-\Delta)^{2}$. Rewriting again and then completing the square (with respect to $\Delta$ ) yield

$$
\{[a+2 n(n+2) c]-\Delta\}^{2}>2 n(n+2) c\left[\left(2 n^{2}+4 n-1\right) c+2 a\right] .
$$

Since $a+2 n(n+2) c>\Delta$ and the right-hand side is positive, we can take the square root of both sides of the above inequality. Doing this and rewriting yield

$$
\begin{aligned}
\Delta & <a+2 n(n+2) c-\sqrt{2 n(n+2) c\left[\left(2 n^{2}+4 n-1\right) c+2 a\right]} \\
& =a+2 n(n+2) c\left[1-\frac{\sqrt{\left(2 n^{2}+4 n-1\right) c+2 a}}{\sqrt{2 n(n+2) c}}\right] \\
& =a+2 n(n+2) c\left[\frac{1-\frac{\left(2 n^{2}+4 n-1\right) c+2 a}{2 n(n+2) c}}{1+\sqrt{\frac{\left(2 n^{2}+4 n-1\right) c+2 a}{2 n(n+2) c}}}\right] \\
& =a+2 n(n+2) c\left[\frac{\frac{2 n(n+2) c-\left(2 n^{2}+4 n-1\right) c-2 a}{2 n(n+2) c}}{1+\sqrt{\frac{\left(2 n^{2}+4 n-1\right) c+2 a}{2 n(n+2) c}}}\right],
\end{aligned}
$$

which simplifies to $\Delta<\varphi(a, c, n)$.

Proof of Proposition 4. As $c$ approaches $E(a), b X^{*}$ must approach zero for (6) to hold. Moreover, $E C S^{*}$ approaches zero as $b X^{*}$ approaches zero, 
whereas

$$
\lim _{c \rightarrow E(a)} E C S_{B}=\frac{n^{2} \int_{E(a)}^{\bar{\alpha}}(a-E(a))^{2} f(a) d a}{2 b(n+1)^{2}}>0 .
$$

Thus, $\Delta C S>0$ for $c$ close to $E(a)$.

\section{References}

Amir, Rabah (1996), "Cournot Oligopoly and the Theory of Supermodular Games," Games and Economic Behavior 15: 132-148.

Amir, Rabah, and Val E. Lambson (2000), "On the Effects of Entry in Cournot Markets," Review of Economic Studies 67: 235-254.

Basar, Tamer, and Yu-Chi Ho (1974), "Informational Properties of the Nash Solutions of the Stochastic Nonzero-Sum Games," Journal of Economic Theory 7: 370-387.

Clarke, Richard N. (1983), Collusion and the Incentives for Information Sharing," Bell Journal of Economics 14: 383-394.

Gal-Or, Esther (1985), "Information Sharing in Oligopoly," Econometrica 53: 329-343.

Gal-Or, Esther (1986), "Information Transmission-Cournot and Bertrand Equilibria," Review of Economic Studies 53: 85-92.

Kühn, Kai-Uwe (2001), "Fighting Collusion by Regulating Communication between Firms," Economic Policy 32: 167-204.

Kühn, Kai-Uwe, and Xavier Vives (1995), "Information Exchanges Among Firms and their Impact on Competition," European Commission Document.

Li, Lode (1985), "Cournot Oligopoly with Information Sharing," RAND Journal of Economics 16, 521-536.

Malueg, David A., and Shunichi O. Tsutsui (1998), "Oligopoly Information Exchange when Non-Negative Price and Output Constraints May Bind," Australian Economic Papers 37: 363-371. 
Novshek, William (1985), "On the Existence of Cournot Equilibrium," Review of Economic Studies 52: 85-98.

Novshek, William, and Hugo Sonnenschein (1982), "Fulfilled Expectations Cournot Duopoly with Information Acquisition and Release," Bell Journal of Economics 13: 214-218.

Ponssard, Jean-Pierre (1979), "The Strategic Role of Information on the Demand Function in an Oligopolistic Market," Management Science 25: 243250.

Radner, Roy (1962), "Team Decision Problems," Annals of Mathematical Statistics 33: 857-881.

Raith, Michael (1996), "A General Model of Information Sharing in Oligopoly," Journal of Economic Theory 71: 260-288.

Sakai, Yasuhiro, and Takehiko Yamato (1989), "Oligopoly, Information and Welfare," Journal of Economics 49: 3-24.

Selten, Reinhard (1970), Preispolitik der Mehrproduktunternehmung in der statischen Theorie. Berlin, Germany: Springer-Verlag.

Shapiro, Carl (1986), "Exchange of Cost Information in Oligopoly," Review of Economic Studies 53: 433-446.

Vives, Xavier (1984), "Duopoly Information Equilibrium: Cournot and Bertrand," Journal of Economic Theory 34, 71-94.

Vives, Xavier (1990), "Trade Association Disclosure Rules, Incentives to Share Information, and Welfare," RAND Journal of Economics 21, 409-430.

Vives, Xavier (1999), Oligopoly Pricing: Old Ideas and New Tools, Cambridge, MA: MIT Press.

Weitzman, Martin L. (1974), "Prices vs. Quantities," Review of Economic Studies 41: 477-491. 


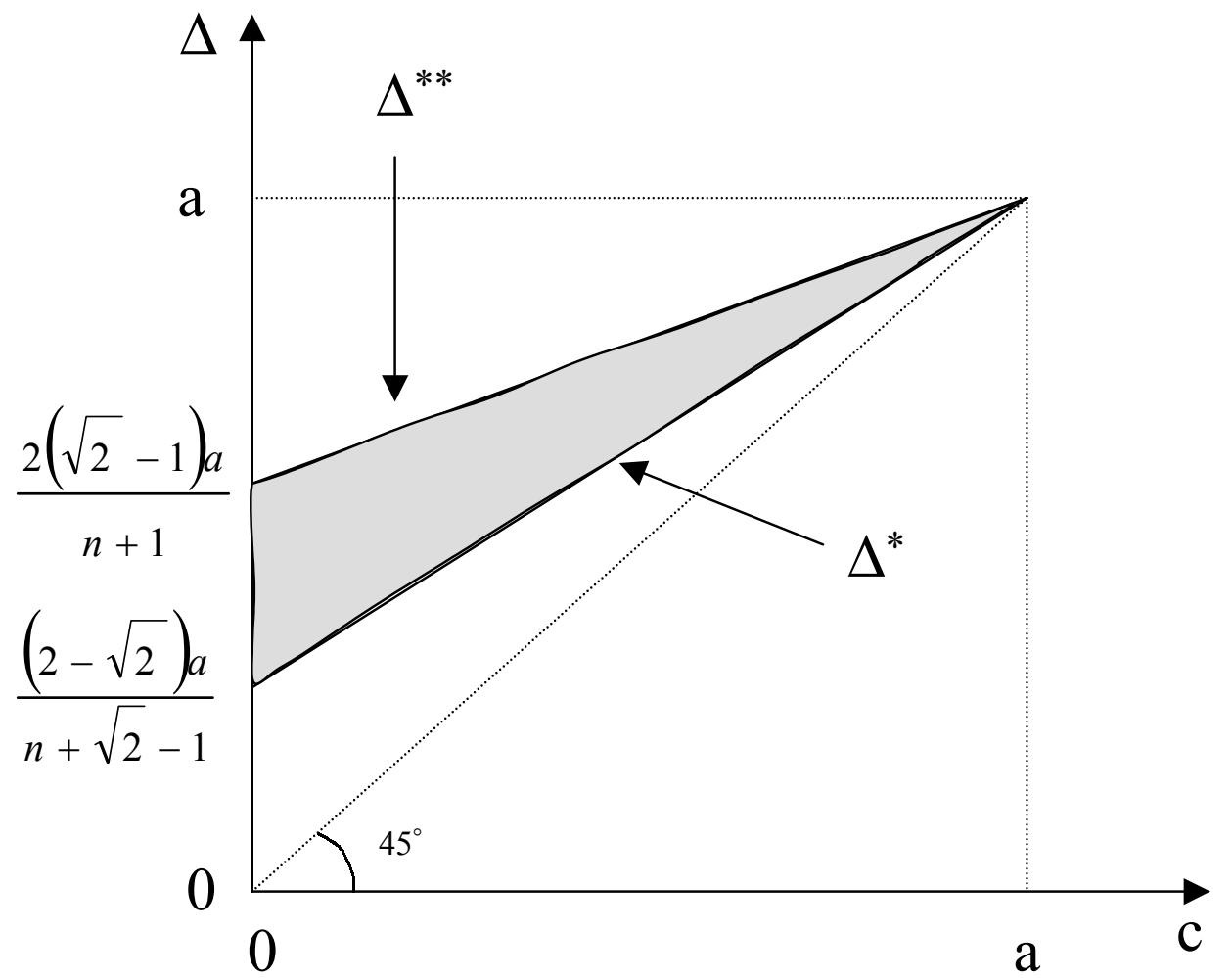

Fig. 1. An equilibrium left of the kink exists beneath $\Delta^{* *}$, and an equilibrium right of the kink exists above $\Delta^{*}$. Hence, in the shadowed area between $\Delta^{*}$ and $\Delta^{* *}$ both equilibria exist. 


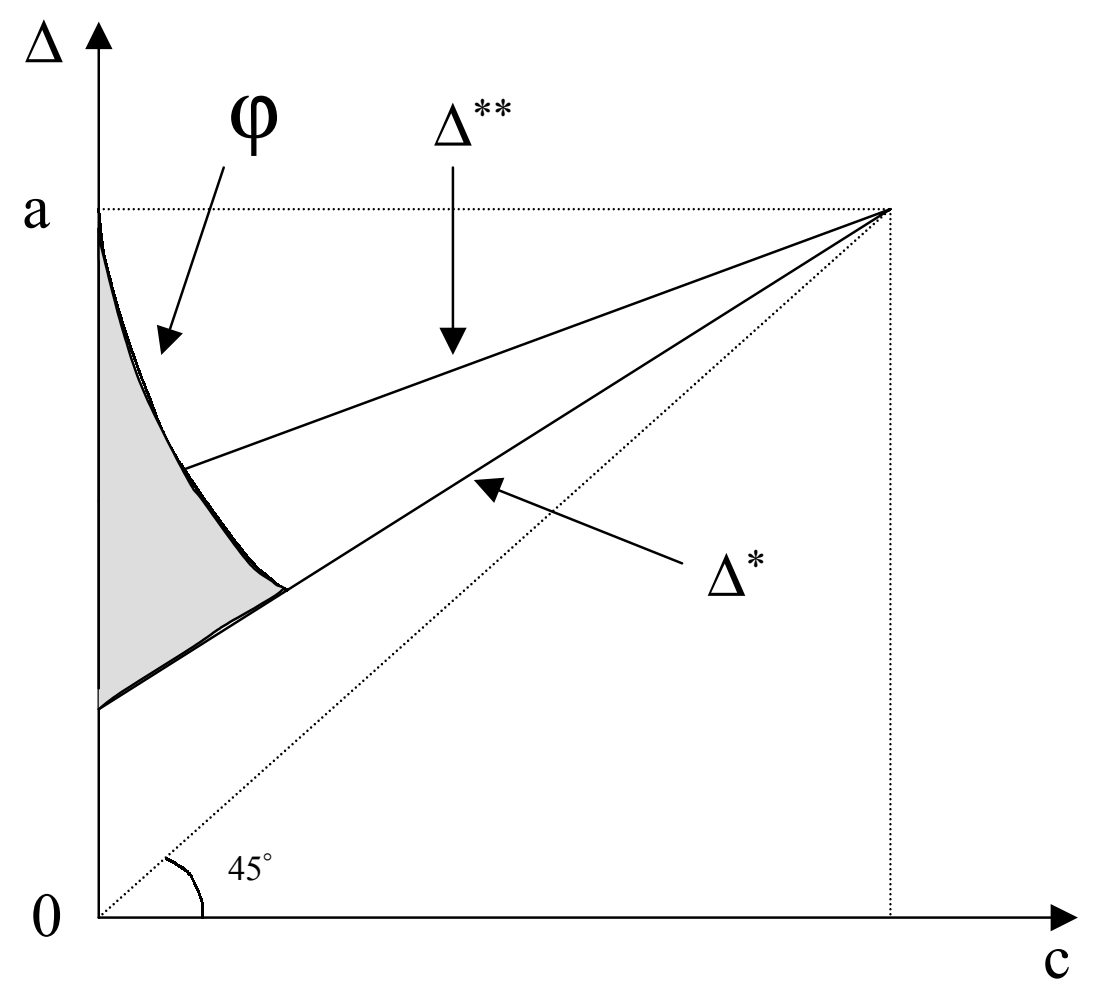

Fig. 2. In the shadowed region is, given that an equilibrium right of the kink is played, expected total surplus lower when the firms know demand than when they do not. 


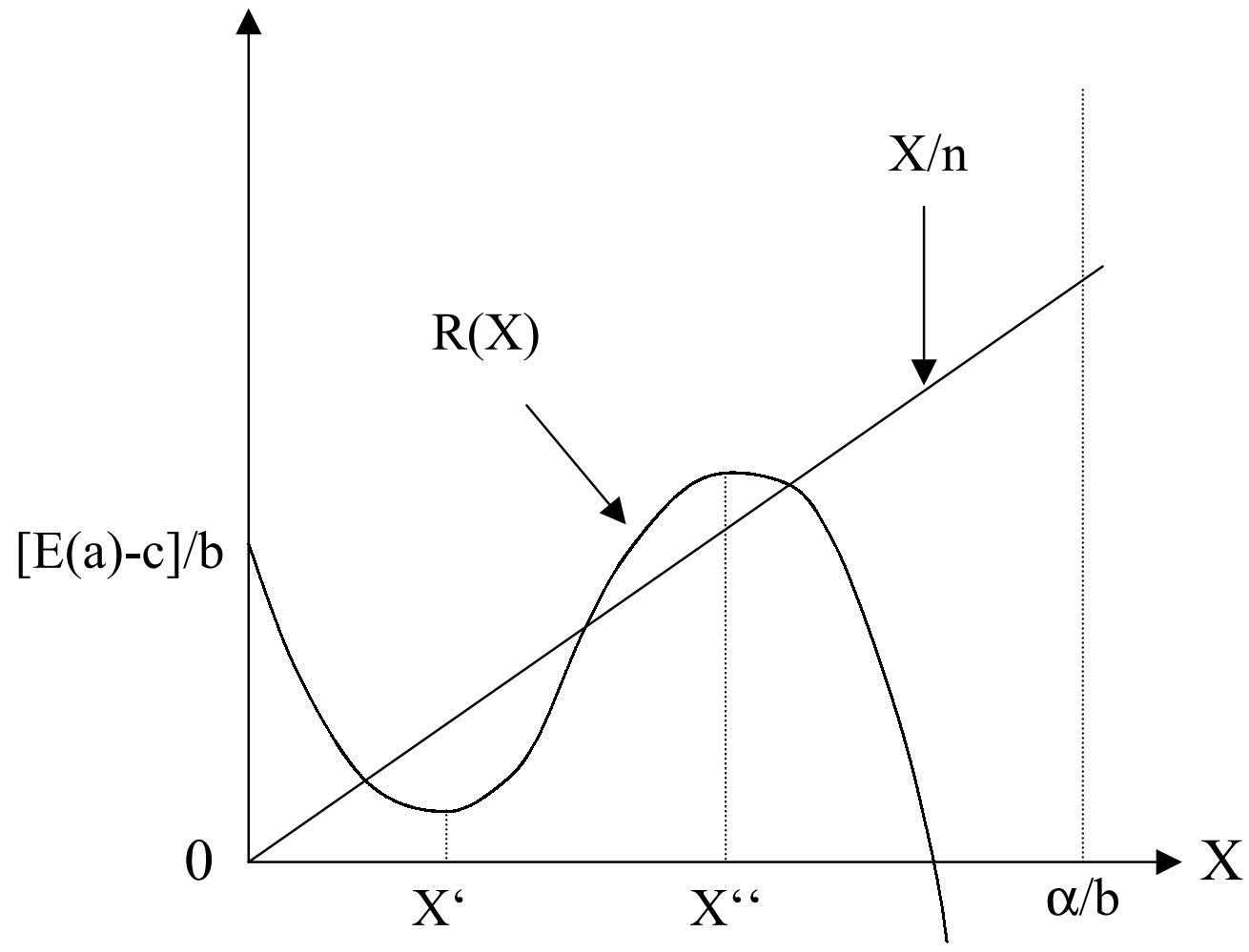

Fig. 3. The shape of $R(X)$, given that there exist more than one equilibrium. 
Bücher des Forschungsschwerpunkts Markt und politische Ökonomie

Books of the Research Area Markets and Political Economy

Andreas Stephan

Essays on the Contribution of Public Infrastructure to Private: Production and its Political

Economy

2002, dissertation.de

Hans Mewis

Essays on Herd Behavior and Strategic

Delegation

2001, Shaker Verlag

Andreas Moerke

Organisationslernen über Netzwerke - Die

personellen Verflechtungen von

Führungsgremien japanischer

Aktiengesellschaften

2001, Deutscher Universitäts-Verlag

Silke Neubauer

Multimarket Contact and Organizational Design

2001, Deutscher Universitäts-Verlag

Lars-Hendrik Röller, Christian Wey (Eds.)

Die Soziale Marktwirtschaft in der neuen

Weltwirtschaft, WZB Jahrbuch 2001

2001, edition sigma

Michael Tröge

Competition in Credit Markets: A Theoretic

Analysis

2001, Deutscher Universitäts-Verlag

Tobias Miarka

Financial Intermediation and Deregulation:

A Critical Analysis of Japanese Bank-Firm-

Relationships

2000, Physica-Verlag

Rita Zobel

Beschäftigungsveränderungen und organisationales Lernen in japanischen Industriengesellschaften

2000, Humboldt-Universität zu Berlin

http://dochost.rz.hu-berlin.de/dissertationen/zobel-

rita-2000-06-19

Jos Jansen

Essays on Incentives in Regulation and Innovation

2000, Tilburg University

Ralph Siebert

Innovation, Research Joint Ventures, and

Multiproduct Competition

2000, Humboldt-Universität zu Berlin

http://dochost.rz.hu-berlin.de/dissertationen/siebert-

ralph-2000-03-23/

Damien J. Neven, Lars-Hendrik Röller (Eds.)

The Political Economy of Industrial Policy in

Europe and the Member States

2000, edition sigma
Jianping Yang

Bankbeziehungen deutscher Unternehmen: Investitionsverhalten und Risikoanalyse 2000, Deutscher Universitäts-Verlag

Christoph Schenk

Cooperation between Competitors -

Subcontracting and the Influence of Information, Production and Capacity on Market Structure and Competition

1999, Humboldt-Universität zu Berlin

http://dochost.rz.hu-berlin.de/dissertationen/schenk-

christoph-1999-11-16

Horst Albach, Ulrike Görtzen, Rita Zobel (Eds.)

Information Processing as a Competitive

Advantage of Japanese Firms

1999, edition sigma

Dieter Köster

Wettbewerb in Netzproduktmärkten

1999, Deutscher Universitäts-Verlag

Christian Wey

Marktorganisation durch Standardisierung: Ein

Beitrag zur Neuen Institutionenökonomik des

Marktes

1999, edition sigma

Horst Albach, Meinolf Dierkes, Ariane Berthoin Antal, Kristina Vaillant (Hg.)

Organisationslernen - institutionelle und

kulturelle Dimensionen

WZB-Jahrbuch 1998

1998, edition sigma

Lars Bergman, Chris Doyle, Jordi Gual, Lars

Hultkrantz, Damien Neven, Lars-Hendrik Röller,

Leonard Waverman

Europe's Network Industries: Conflicting

Priorities - Telecommunications

Monitoring European Deregulation 1

1998, Centre for Economic Policy Research

Manfred Fleischer

The Inefficiency Trap

Strategy Failure in the

German Machine Tool Industry

1997, edition sigma

Christian Göseke

Information Gathering and Dissemination

The Contribution of JETRO to

Japanese Competitiveness

1997, Deutscher Universitäts-Verlag 
Fredrik Andersson

Kai A. Konrad

Lars-Hendrik Röller

Christian Wey

Talat Mahmood Klaus Schömann

Talat Mahmood Klaus Schömann

Jos Jansen

Jos Jansen

Günter Franke Harris Schlesinger Richard C. Stapleton

Tomaso Duso

Johan Lagerlöf

Paul Heidhues

Olivier Cadot Lars-Hendrik Röller Andreas Stephan

Justus Haucap

Christian Wey

Heidrun C. Hoppe Emre Ozdenoren

Rainer Nitsche

Daniel Krähmer

J. Peter Murmann

Kai A. Konrad

Robert Nuscheler

Fredrik Andersson Kai A. Konrad
Human Capital Investment and Globalization in Extortionary States

Merger Control in the New Economy

Die Determinanten der Mirgrationsentscheidung von IT-Hochschulabsolventen aus Pakistan Empirische Befunde zur Ausgestaltung der deutschen „Green Card“

The Determinants of the Migration Decision of ITgraduates from Pakistan: Empirical Evidence for the Design of a German "Green Card"

The Effects of Disclosure Regulation on Innovative Firms: Common Values

The Effects of Disclosure Regulation on Innovative Firms: Private Values

Multiplicative Background Risk

On the Politics of the Regulatory Reform:

Econometric Evidence from the OECD Countries

On the Desirability of an Efficiency Defense in

Merger Control

Contribution to Productivity or Pork Barrel? The Two Faces of Infrastructure Investment

Unionization Structures and Firms' Incentives for Productivity Enhancing Investments

Intermediation in Innovation

On the Effectiveness of Anti-Predation Rules

Entry and Experimentation in

Oligopolistic Markets for Experience Goods

The Coevolution of Industries and National Institutions: Theory and Evidence

Terrorism and the State

Physician Reimbursement, Time-Consistency and the Quality of Care

Taxation and Education Investment in the Tertiary Sector
FS IV $02-06$

FS IV $02-11$

FS IV $02-12$

FS IV $02-15$

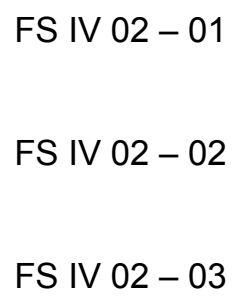

FS IV $02-02$ 
Jan Boone

Kai A. Konrad

Helmut Bester

Kai A. Konrad

Kjell Erik Lommerud Bjørn Sandvik

Odd Rune Straume

Steffen Huck Vicki Knoblauch Wieland Müller

Ralph Siebert

Jürgen Bracht

Saul Lach

Eyal Winter

Steffen Huck

Kai A. Konrad

Daniel Krähmer

Thomas Knaus

Robert Nuscheler

Kurt R. Brekke

Robert Nuscheler

Odd Rune Straume

Kai A. Konrad

Sebastian Kessing

Sebastian Kessing

Michal Grajek

Robert M. Adams Lars-Hendrik Röller

Robin C. Sickles

Tomaso Duso

Damien J. Neven Lars-Hendrik Röller

Tomaso Duso Astrid Jung
'Be nice, unless it pays to fight': A New Theory of

Price Determination with Implications for

Competition Policy

Altruism and Envy in Contests:

An Evolutionarily Stable Symbiosis

Delay in Contests

Good Jobs, Bad Jobs and Redistribution

On the Profitability of Collusion in Location Games

Learning by Doing and Multiproduction Effects over the Life Cycle: Evidence from the

Semiconductor Industry

Modeling Oligopolistic Price Adjustment in Micro

Level Panel Data

Strategic Trade Policy and the Home Bias in Firm

Ownership Structure

Delegation versus Authority

Incomplete Risk Adjustment and Adverse

Selection in the German Public Health Insurance System

Quality and Location Choices under Price

Regulation

Inverse Campaigning

A Note on the Determinants of Labour Share Movements

Employment Protection and Product Market Competition

Identification of Network Externalities in Markets for Non-Durables

Market Power in Outputs and Inputs: An Empirical Application to Banking

The Political Economy of European Merger Control: Evidence using Stock Market Data

Market Conduct and Endogenous Lobbying: Evidence from the U.S. Mobile Telecommunications Industry
FS IV $02-20$

FS IV $02-21$

FS IV $02-22$

FS IV $02-28$

FS IV $02-29$

FS IV $02-18$

FS IV $02-19$

FS IV $02-23$

FS IV $02-24$

FS IV $02-25$

FS IV $02-26$

FS IV $02-27$

FS IV $02-30$

FS IV $02-31$

FS IV $02-32$

FS IV $02-33$

FS IV $02-34$

FS IV $02-35$ 
Anette Boom Investments in Electricity Generating Capacity under Different Market Structures and with Endogenously Fixed Demand

Kai A. Konrad Wolfram F. Richter Stergios Skaperdas

Johan Lagerlöf
Zur Berücksichtigung von Kindern bei umlagefinanzierter Alterssicherung

Restraining the Genuine Homo Economicus: Why the Economy cannot be divorced from its Governance

Insisting on a Non-Negative Price: Oligopoly, Uncertainty, Welfare, and Multiple Equilibria
SP || $2003-01$

SP || $2003-02$

SP || $2003-03$

SP || $2003-04$ 
Bei Ihren Bestellungen von WZB-Papers schicken

Sie bitte unbedingt einen an Sie adressierten Auf-

kleber mit sowie je paper eine Briefmarke im Wert

von 0,51 Euro oder einen "Coupon Reponse Inter-

national " (für Besteller aus dem Ausland)
Please send a self addressed label and postage stamps in the amount of 0.51 Euro or a "CouponReponse International" (if you are ordering from outside Germany) for each WZB-paper requested

Absender / Return Address:

Wissenschaftszentrum Berlin

für Sozialforschung

Presse- und informationsreferat

Reichpietschufer 50

D-10785 Berlin-Tiergarten

Hiermit bestelle ich folgende(s)

Discussion paper(s):

Please send me the following Discussion paper(s):

Bestell-Nr. / Order no.

Autor/in, Kurztitel /Author(s) / Title(s) in brief 